DOI: $10.15593 / 2224-9354 / 2019.3 .17$

УДК $005.342(470+571)$

\title{
М.В. Маракулин
}

\section{ИНТЕГРАЛЬНАЯ СТРУКТУРА ИННОВАЦИОННОЙ СИСТЕМЫ ЭНЕРГЕТИЧЕСКОГО МЕНЕДЖМЕНТА В РОССИЙСКОЙ ФЕДЕРАЦИИ}

\begin{abstract}
Обозначены перспективы развития рынка энергосервисных услуг в Российской Федерации и главные причины его изменений. По мере интеграции экономики современной России в глобальную экономическую систему будет расти роль той части управленческой деятельности, которая направлена на оптимизацию и экономичное расходование всех видов потребляемых экономикой ресурсов, в том числе энергетических ресурсов. Трансформация системы современного энергетического менеджмента в России в безусловном порядке будет характеризоваться все более сложными процессными процедурами, направленными на решение задач по энергосбережению. В статье рассмотрена формирующаяся в настоящее время интегральная структура энергетического менеджмента, а также некоторые процессные моменты, подтверждающие указанный ход построения иерархической структуры современного менеджмента в сфере энергосбережения в Российской Федерации.

Рассмотренный в статье процесс синтеза иерархии системы энергетического менеджмента имеет сложный характер. Стоит задача не только освоения имеющихся инновационных практик мирового уровня, но и создания современной национальной системы подготовки кадров, нацеленных на освоение технологий общего ресурсосбережения. При этом особенно заметны существующие недостатки в отдельных законодательных документах федерального уровня, определяющих политику развития в сфере энергосбережения. Недостатки отдельных положений и подпрограмм государственной программы РФ «Энергоэффективность и развитие энергетики», а также недостаточная развитость системы управления процессами энергосбережения указывают на отсутствие в России современного энергоменеджмента. В статье показаны основные направления по преодолению сложившейся ситуации. Определен ряд основных факторов, генерирующих запрос участников экономической деятельности на энергосервис, роль которого в дальнейшем будет возрастать.

Ключевые слова: энергосбережение, энергоэффективность, энергосервис, энергосервисный контракт, законодательство в сфере регулирования энергосберегающей деятельности.
\end{abstract}

Процесс энергосбережения (ЭСб), являясь элементом общей системы оптимизации ресурсопотребления, через механизм энергосервиса (ЭС), снижает зависимость от использования неэффективных и опасных источников энергии [1], способствует росту фондоотдачи основных производственных фондов, оборудования, снижает издержки, стимулирует освоение новых технологий и создание новых рынков энергоемкой продукции, услуг и высокотехнологичных рабочих мест, что подразумевает применение инновационных ресурсосберегающих подходов в оптимизации корпоративных бизнес-

(C) Маракулин М.В., 2019

Маракулин Михаил Васильевич - канд. экон. наук, доцент кафедры «Менеджмент» ФГБОУ ВО «Пермский государственный национальный исследовательский университет», e-mail: marakperm@mail.ru. 
процессов [2]. В результате ЭСб становится в настоящее время одним из ключевых факторов перехода энергоемких экономик на устойчивое развитие. По экспертным оценкам, рынок услуг ЭС в России [3] имеет хорошие перспективы. Так, согласно перспективным расчетам Российского энергетического агентства Министерства энергетики РФ [4], мировые рынки энергосервисных услуг, как в развитых странах, так и в России, ждет значительный рост (рис. 1).

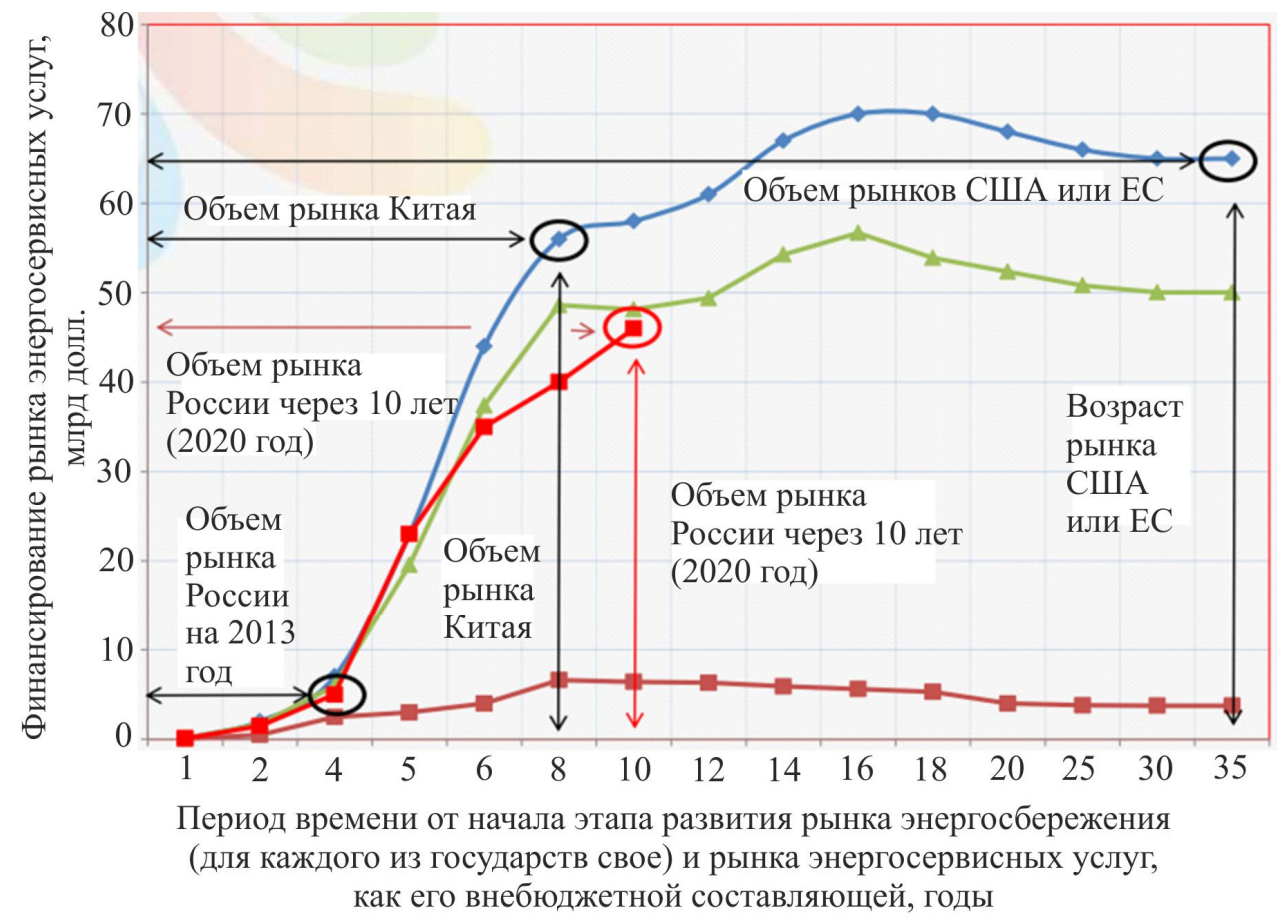

Рис. 1. Экспертные прогнозы роста мирового рынка энергосервисных услуг, включая перспективы роста рынка в России

Согласно приведенному графику развития, объем рынка услуг ЭС может составить примерно 46 млрд \$ к 2020 г. По другим экспертным оценкам, проведенным в 2014 г. емкость российского рынка ЭС [5], составляет 3,5 трлн руб. ежегодно.

Одна из причин прогнозируемого роста спроса на услуги ЭС состоит в том, что российская экономика значительно (в 2-4 раза) превосходит развитые экономики мира по затратам энергетических ресурсов (ЭР) на единицу произведенной продукции. Кроме того, аналитики и эксперты в области поставок энергоресурсов (ЭР) едины во мнении о том, что на мировом рынке стоимость ЭР будет увеличиваться. Отсюда следует вывод о безусловной необходимости для большинства российских производителей принимать меры 
по ЭСб с тем, чтобы сохранять возможности исповедовать бизнес-стратегии низких издержек, как базисных стратегий, обеспечивающих конкурентоспособность российского бизнеса. И в этом случае развитие ЭМ в российском корпоративном менеджменте станет безусловной как организационноуправленческой, так и технологической инновацией.

При этом необходимо вести речь о создании, развитии и совершенствовании энергоменеджмента (ЭМ) как системной составляющей государственного, муниципального и корпоративного менеджмента [6]. Здесь следует указать, что проблема создания ЭМ перед мировой хозяйственной системой не стоит, поскольку вопрос его создания в мировой практике успешно решен. ЭМ как системное понятие хорошо разработан, структурирован и является обычным атрибутом как бизнес-структур, так и органов власти на местах. Кроме того, в мировой практике ЭМ давно уже является элементом более широкой системы менеджмента ресурсосбережения. Поскольку стоит задача синтеза практической системы ЭМ в широком корпоративном и государственном масштабе, в России необходимо создавать ЭМ на системном, современном уровне, используя имеющийся мировой опыт. В связи с этим возникла необходимость освоения как широких мировых технологических практик, так и управленческих подходов и современных управленческих методов организации ЭМ. Необходимо развивать систему подготовки специалистов управленческого профиля (менеджеров) [7], имеющих специализацию «Ресурсосбережение» как системной составляющей при формировании конкурентоспособности российских компаний. Отметим, что в целях развития ЭСб деятельности в Российской Федерации идет работа по формированию и развитию ЭМ [8], однако этого недостаточно. Современные исследования специфичного рынка ЭС отмечают необходимость подготовки как специалистов по реализации ЭСб мероприятий, так и управленцев, организующих реализацию ЭС контрактов и программ для ведения ЭСб деятельности, причем и в бюджетной сфере, и в государственных органах власти, и в сфере коммерческой деятельности [9]. Кроме того, действенная система ЭМ должна быть всеобъемлющей, т.е. представлять собой структурно-ярусную модель развития и включать в себя все уровни совершенствования управленческой иерархии (рис. 2).

Другими словами, национальная система развития ЭМ будет понастоящему действенной и высокоэффективной при условии непрерывного развития и совершенствования на всех уровнях управленческой иерархии, как на федеральном (макроуровне), региональном и муниципальном (мезоуровне), так и на корпоративном (микроуровне).

Необходимо отметить, что российские органы федеральной власти достаточно последовательно занимаются формированием политики, направленной на стимулирование процессов ЭСб в экономике [10]. В Российской Федерации создается законодательная база, регулирующая вопросы ЭСб. 

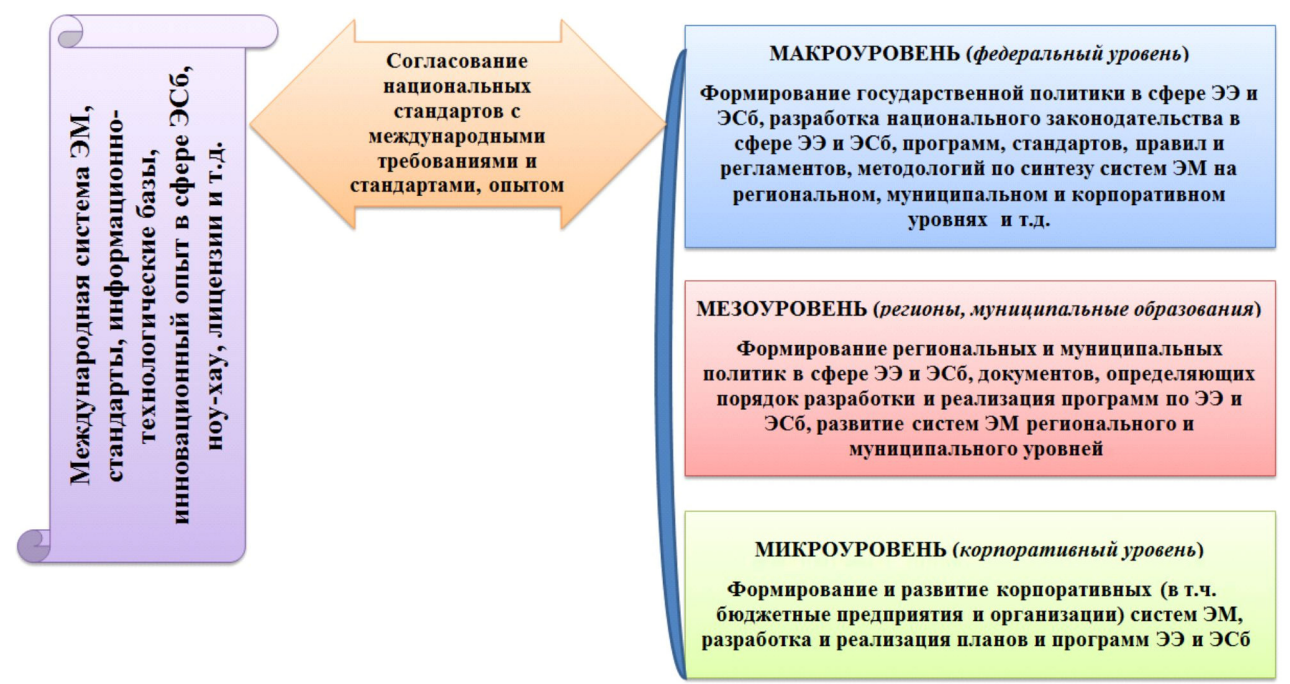

Рис. 2. Ярусная модель структуры интегральной системы энергетического менеджмента в Российской Федерации

Основные направления государственной политики в сфере ЭСб определены Федеральным законом «Об энергосбережении и о повышении энергетической эффективности...» [11], а также распоряжением Правительства РФ № 1830-р «Об утверждении плана мероприятий по энергосбережению и повышению энергетической эффективности в Российской Федерации». Приказ № 182 Министерства энергетики РФ положил начало процессу обязательной паспортизации государственных, муниципальных предприятий и учреждений, предприятий, занятых добычей, производством, транспортировкой и передачей ЭР, а также крупных потребителей энергии. Закон №131-Ф3 «Об общих принципах организации МСУ в РФ» определил обязанности органов местного самоуправления в решении вопросов ЭСб на муниципальном уровне. В 2010 г. введена в действие государственная программа РФ «Энергосбережение и повышение энергетической эффективности на период до 2020 года», однако в 2014 г. она была аннулирована по ряду причин и в том же году введена в действие государственная программа РФ «Энергоэффективность и развитие энергетики» рассчитанная на период до 2020 г. Правительством РФ разработаны и внедряются целевые программы ЭСб «Энергоэффективный квартал», «Малая энергетика» и целый ряд других. В профессиональном сообществе в настоящее время обсуждается Комплексный план повышения энергоэффективности (ЭЭ) экономики России [12], разработанный Министерством экономического развития РФ. В структуре федеральной исполнительной власти РФ определена организация ФГБУ «Российское энергетическое агентство» Министерства энергетики РФ, которая занимается 
сбором данных, связанных с ресурсосбережением и повышением ЭЭ и занимается информационно-методологическим обеспечением процессов ЭСб в России. Успешно работает интернет-портал Государственной информационной системы в области энергосбережения и повышения энергетической эффективности (ГИСЭЭ). Всего в реестре ГИСЭЭ на момент публикации статьи размещено 113 законодательных нормативно регулирующих документов федерального уровня, определяющих политику федеральных органов власти в сфере ЭЭ.

Государственная программа РФ «Энергоэффективность и развитие энергетики» будет действовать до конца 2020 г. Основным целевым показателем государственной программы является снижение энергоемкости валового внутреннего продукта (ВВП) Российской Федерации в 2020 г. на 9,41% от показателя ВВП 2007 г. Исполнителем подпрограммы является Министерство энергетики Российской Федерации. Структурно государственная программа состоит из семи подпрограмм. Пять из них ориентированы на совершенствование энергоэффективности в следующих отраслях: электроэнергетика, нефтяная отрасль, газовая отрасль, угольная и торфодобывающая промышленности и сектор возобновляемых источников энергии. Еще одна подпрограмма является сервисной для шести целевых подпрограмм. Самая первая подпрограмма государственной программы «Энергосбережение и повышение энергетической эффективности» сосредоточена на построении системы управления, обеспечивающей реализацию государственной политики в сфере ЭСб и ЭЭ. Общие расходы на реализацию государственной программы определены в 104 млрд руб. Расходы на исполнение подпрограммы «Энергосбережение и повышение энергетической эффективности» должны составить 14 млрд руб. Указанная сумма (213 млн \$ по курсу ЦБ РФ на 26.10.2018), предназначенная для развития инфраструктуры ЭСб деятельности в России в течение 8 лет, представляется явно не достаточной для полноценного развития рынка, прогноз объема которого оценивается примерно в 46 млрд \$ к 2020 г. (см. рис. 1). Среди замечаний, которые возникают непосредственно к самой подпрограмме «Энергосбережение и повышение энергетической эффективности» государственной программы с точки зрения ее соответствия реализации государственной политики в сфере ЭЭ и ЭСб, необходимо отметить следующие. Подпрограммой предусмотрено, что доля профильных отраслевых государственных программ Российской Федерации и субъектов РФ, а также соответствующих программ компаний с государственным участием - крупнейших потребителей энергетических ресурсов в топливно-энергетическом комплексе России, содержащих показатели в области энергосбережения и повышения энергетической эффективности к 2020 г., составит всего 45 \%. На наш взгляд, к концу срока исполнения государственной программы указанный показатель должен приближаться к 100 \%, поскольку речь идет об отношении государст- 
венных органов управления к проведению государственной же политики! Точно такое же недоумение вызывают планы государственной программы довести до 40 (!) количество субъектов Российской Федерации, которым надлежит создать юридические лица, наделенные полномочиями по реализации и предоставлению финансовой помощи на мероприятия (проекты) в области энергосбережения и повышения энергетической эффективности. На момент подготовки статьи к публикации в составе Российской Федерации состояло 85 субъектов государственности. С точки зрения реализации государственной политики наиболее правильно и эффективно было бы осуществлять эту политику на территории всей Российской Федерации, а не в менее чем половине ее субъектов.

Говоря о проведении политики ЭСб на мезоуровне и о формировании системы энергоменеджмента в государственных региональных и муниципальных органах власти, следует сказать, что проблемы повышенных расходов ЭР в отраслях хозяйства обозначены многими региональными [13] и муниципальными органами управления [14]. По сведениям некоммерческого партнерства «Энергоэффективный город» (http://energosovet.ru) на уровне региональных государственных органов власти принято 547 нормативноправовых документов по ЭСб. Документы, программы и законодательные акты, определяющие политику в сфере ЭСб, принимаются и на муниципальном уровне. Не менее 50 регионов РФ имеют региональные программы действий в сфере ЭСб [15]. Однако благодаря разнообразию региональных и местных условий в РФ наилучшего и относительно быстрого успеха смогут добиться регионы, которые умеют воспользоваться своими конкурентными преимуществами. Это позволит регионам выйти на передовые позиции в области внедрения ЭСб технологических и управленческих процедур [16]. Для придания динамики процессу развития ЭМ в регионах и муниципальных образованиях РФ необходим целый комплекс системных мер, а именно: совершенствование методической базы разработки, формирования и внедрения системы ЭМ в организациях; совершенствование нормативно-законодательной базы федерального и регионального уровней; формирование системы подготовки и развития кадров [17], как управленческой направленности по специальности «Энергоменеджмент», так и технической по инженерным специальностям, связанным с использованием различных видов ЭР, а также разработка, внедрение и совершенствование учебных программ, методик и стандартов подготовки специалистов в указанных сферах; разработка мер поддержки и стимулирования субъектов хозяйствования для ведения деятельности по ЭСб; активное развитие инфраструктуры для ведения деятельности по ЭСб.

Говоря о развитии системы ЭМ на корпоративном микроуровне, необходимо отметить, что практика ведения ЭСб деятельности указывает на воз- 
можность возникновения дополнительного экономического эффекта [18], синергии от внедрения корпоративного ЭМ. Например, при внедрении частотно-регулируемых приводов на электродвигателях (ЭД), работающих на переменных нагрузках, не только снижаются объемы потребляемой ЭД электрической энергии, но и снижается его износ, а также износ приводимых им в действие исполнительных механизмов и агрегатов. Это ведет к заметному уменьшению издержек на текущее обслуживание и все виды ремонтов используемого в единой с регулируемым ЭД технологической цепочке оборудования. Кроме того, необходимо отметить, что в силу ряда причин законодательного свойства, при проведении ЭСб деятельности наибольший риск несут ЭС компании [19]. Согласно исследованию эффективности системы ЭМ крупнейших предприятий Российской Федерации, проведенному в 2015 г. Российским энергетическим агентством Министерства энергетики Российской Федерации среди 80 предприятий разной отраслевой направленности, основными проблемами внедрения системы ЭМ на предприятиях России является несовершенство методологической базы, не позволяющей компаниям технологично и качественно разрабатывать технико-экономические обоснования и экономическую эффективность мероприятий по повышению ЭЭ, а также низкий уровень информированности менеджмента компаний о системах ЭМ, лучших практиках разработки и внедрения систем ЭМ, и неразвитость инфраструктуры ЭС.

Какие факторы явно влияют на развитие современных корпоративных систем ЭМ? Прежде всего, усиление конкуренции, возникающей вследствие роста темпов внедрения инноваций, позволяющих снижать долю использования ЭР на единицу товара/услуги при производстве, продвижении, реализации и утилизации. Вторым фактором, «стимулирующим» развитие ЭСб деятельности в России, является стабильный рост цен на энергию и ее носители в стране. Существует экспертное мнение [20], согласно которому современные вертикально-интегрированные корпоративные структуры ТЭК, фактически монопольно контролируют всю технологическую цепочку от добычи, транспортировки, переработки, до доставки и сбыта энергоресурсов каждому конкретному потребителю. В условиях монопольного владения рынком российские предприятия ТЭКа ориентируются на рост доходности [21], который легко достигается через рост цен и тарифов на энергию. Это означает, что российскому бизнесу жизненно необходимо заниматься ЭСб, для того чтобы в структуре себестоимости его продукции доля ЭР оставалась/снижалась в целях сохранения конкурентных позиций продукции на глобальном рынке. И, наконец, третий фактор, способствующий развитию ЭСб в России, - макроэкономический, а именно - относительно низкая ставка рефинансирования Центрального банка России позволяет надеяться, что будет расширяться перечень ЭСб мероприятий, имеющих большой срок окупаемости, предлагаемых ЭС компаниями своим клиентам. 


\section{Список литературы}

1. Энергоэффективность и устойчивое развитие / С.Н. Бобылев [и др.]; под ред. В.М. Захарова; Ин-т устойчивого развития / Центр экол. политики России. - М., 2010. - 148 с.

2. Эволюция концепции устойчивого развития в контексте исторических процессов / Т.В. Алферова, Е.А. Третьякова, М.Ю. Осипова, Ю.И. Суркова. М.: ИНФРА-М, 2018. -188 с.

3. Мукумов Р.Э., Андрианов В.В., Захаров А.П. Развитие рынка энергосервиса в России. Состояние и перспективы / Энергосовет. - 2012. № 6 (25). - C. 26-30.

4. Туликов А.В. Состояние и перспективы развития рынка энергосервисных услуг в Российской Федерации [Электронный ресурс]: докл. / Рос. энергет. агентство М-ва энергетики РФ. - URL: http://energoeducation.ru/ files/prez \%204-7 \%20Tulikov.pdf (дата обращения: 20.08.2018).

5. Савчук С. Экономия становится рентабельной // Российская газета. 2014. - № 965 (36).

6. Доможирова К.В., Лохматова В.А. Новый взгляд на управление человеческими ресурсами: компетентностный подход // Повышение производительности труда как ключевое направление региональной промышленной политики и основа неоиндустриального подъема инновационной конкурентоспособности корпораций: материалы VIII Междунар. науч.-практ. конф. Пермь, 2015. - С. 140-142.

7. Алферова Т.В. Концептуальное моделирование практико-ориентированной системы подготовки кадров с позиции компетентностного подхода // Развитие стратегического и проектного управления сетевыми территориально-отраслевыми системами - ключевое направление неоиндустриальной модернизации современной российской экономики: материалы IX Всерос. науч.-практ. конф. - Пермь, 2016. - С. 207-210.

8. Типовая дорожная карта внедрения системы энергетического менеджмента // Портал Государственной информационной системы в области энергосбережения и повышения энергетической эффективности. - URL: http://https://gisee.ru/

9. Шапошникова Т.В. Преимущества и риски энергосервисных контрактов // Молодой ученый. - 2016. - № 6. - С. 969-972.

10. Гершанок А.А. Экономические реформы в России - долгосрочная стратегия или предвыборный популизм // Теория и практика корпоративного менеджмента: сб. науч. ст. / Перм. гос. нац. исслед. ун-т. - Пермь, 2017. Вып. 14. - С. 22-27.

11. Об энергосбережении и о повышении энергетической эффективности и о внесении изменений в отдельные законодательные акты Российской Фе- 
дерации: Федер. закон от 23.11.2009 № 261-Ф3. - Доступ из справ.-правовой системы «КонсультантПлюс».

12. Комплексный план повышения энергоэффективности экономики России [Электронный ресурс] / Аналитический центр при Правительстве Российской Федерации. - URL: http:/ac.gov.ru/files/content/13768/ kompleksnyj-plan-pdf.pdf (дата обращения: 20.08.2018).

13. Незнакина К.В. Региональные программы экономического и социального развития: элемент системы эффективного управления экономикой // Экономика. Управление. Право. - 2012. - № 10-1 (34). - С. 48-50.

14. Елохов А.М., Елохова Т.А. Стратегическое программно-целевое управление / Зап.-Урал. ин-т экон. и права. - Пермь, 2015. - 377 с.

15. Бурчакова А.А. Повышение экономической эффективности энергопотребления с использованием механизма энергосервиса, как фактор перехода на устойчивое развитие // Экономика и предпринимательство. - 2015. № 12-4. - C. 160-167.

16. Modern Russian and foreign approaches to strategic planning of the regional socio-economic development / V.G. Prudskiy, G.A. Demin, A.M. Oshchepkov, A.A. Gershanok // Journal of Advanced Research in Law and Economics. - 2017. Vol. VIII. - Spring, 2(24). - P. 570-580. DOI: 10.14505/jarle.v8.2(24).27

17. Воеводкин Н.Ю., Доможирова К.В. Основы кадровой работы в организации // Прогнозирование инновационного развития национальной экономики в рамках рационального природопользования: материалы V Междунар. науч.-практ. конф.: в 3 ч. - Пермь, 2016. - С. 434-438.

18. Адейкина Т.Н., Антипова Н.В. Энергосервисный контракт как способ реализации политики энергосбережения // Молодежь и наука: сб. материалов Х Юбил. Всерос. науч.-техн. конф. / Сиб. федер. ун-т. - Красноярск, 2014. URL: http://conf.sfu-kras.ru/sites/mn2014/directions.html.

19. Бурчакова А.А. Развитие механизма энергосервиса как направления повышения энергоэффективности: дис. ... канд. экон. наук / МГУ им. М.В. Ломоносова. - М., 2016. - 134 с.

20. Суденко С. Эксперт о Комплексном плане повышения энергоэффективности экономики России // Портал по энергосбережению «Энергосовет». - URL: http://energosovet.ru/news.php?zag=1502446427 (дата обращения: 20.08.2018).

21. Гершанок А.А. Российская экономика на нефтяном пути: проблемы и перспективы инновационного развития предприятий // Индустриальная цивилизация: прошлое или будущее России: материалы III Перм. конгр. ученых-экономистов: в 2 т. / Перм. гос. нац. исслед. ун-т. - Пермь, 2017. - Т. 1. C. 21-25. 


\section{References}

1. Bobylev S.N. [et al.]. Energoeffektivnost' i ustoichivoe razvitie [Energy effeciency and sustainable development]. Ed. V.M. Zakharov. Moscow, Institute of Sustainable Development, Russian Centre for Ecological Policy, 2010, 148 p.

2. Alferova T.V., Tret'iakova E.A., Osipova M.Iu., Surkova Iu.I. Evoliutsiia kontseptsii ustoichivogo razvitiia $\mathrm{v}$ kontekste istoricheskikh protsessov [Evolution of the concept of sustainable development in the context of historical processes]. Moscow, INFRA-M, 2018, 188 p.

3. Mukumov R.E., Andrianov V.V., Zakharov A.P. Razvitie rynka energoservisa v Rossii. Sostoianie i perspektivy [Development of the energy service market in Russia. Status and prospects]. Energosovet, 2012, no. 6 (25), pp. 26-30.

4. Tulikov A.V. Sostoianie i perspektivy razvitiia rynka energoservisnykh uslug v Rossiiskoi Federatsii [Status and prospects of the development of energy service market in the Russian Federation]. Russian Energy Agency, available at: http://energoeducation.ru/files/prez\%204-7\%20Tulikov.pdf (accessed 20 August 2018).

5. Savchuk S. Ekonomiia stanovitsia rentabel'noi [Saving becomes profitable]. Rossiiskaia gazeta, 2014, no. 965 (36).

6. Domozhirova K.V., Lokhmatova V.A. Novyi vzgliad na upravlenie chelovecheskimi resursami: kompetentnostnyi podkhod [A new perspective at human resources management: Competence approach]. Povyshenie proizvoditel'nosti truda kak kliuchevoe napravlenie regional'noi promyshlennoi politiki i osnova neoindustrial'nogo pod"ema innovatsionnoi konkurentosposobnosti korporatsii. Proceedings of VIII Int. Sci.-Pract. Conf., 2015, pp. 140-142.

7. Alferova T.V. Kontseptual'noe modelirovanie praktiko-orientirovannoi sistemy podgotovki kadrov s pozitsii kompetentnostnogo podkhoda [Conceptual modeling of practice-oriented training system from the competence approach perspective]. Razvitie strategicheskogo i proektnogo upravleniia setevymi territorial'no-otraslevymi sistemami - kliuchevoe napravlenie neoindustrial'noi modernizatsii sovremennoi rossiiskoi ekonomiki. Proceedings of IX All-Russ. Sci.Pract. Conf., 2016, pp. 207-210.

8. Tipovaia dorozhnaia karta vnedreniia sistemy energeticheskogo menedzhmenta [Typical roadmap of implementation of energy management system]. Portal Gosudarstvennoi informatsionnoi sistemy $v$ oblasti energosberezheniia $i$ povysheniia energeticheskoi effektivnosti, available at: http://https://gisee.ru/ (accessed 20 August 2018).

9. Shaposhnikova T.V. Preimushchestva i riski energoservisnykh kontraktov [Advantages and risks of energy service contracts]. Molodoi uchenyi, 2016, no. 6, pp. 969-972.

10. Gershanok A.A. Ekonomicheskie reformy v Rossii - dolgosrochnaia strategiia ili predvybornyi populizm [Economic reforms in Russia - a long-term 
strategy or pre-election populism]. Teoriia $i$ praktika korporativnogo menedzhmenta. Perm, Perm State National Research University, 2017, no. 14, pp. 22-27.

11. Ob energosberezhenii i o povyshenii energeticheskoi effektivnosti i o vnesenii izmenenii v otdel'nye zakonodatel'nye akty Rossiiskoi Federatsii [On energy saving and improving energy efficiency and amendments to certain legislative acts of the Russian Federation]. Federal law of Nov. 23, 2009 no. 261-FZ. Available at: ConsultantPlus Digital Reference System.

12. Kompleksnyi plan povysheniia energoeffektivnosti ekonomiki Rossii [Comprehensive plan of improving the energy efficiency of the Russian economy]. Analiticheskii tsentr pri Pravitel'stve Rossiiskoi Federatsii, avaialable at: http://ac.gov.ru/files/content/13768/kompleksnyj-plan-pdf.pdf (accessed 20 August 2018).

13. Neznakina K.V. Regional'nye programmy ekonomicheskogo i sotsial'nogo razvitiia: element sistemy effektivnogo upravleniia ekonomikoi [Regional programs of economic and social development: An element of an effective management economic system]. Ekonomika. Upravlenie. Pravo, 2012, no. 10-1 (34), pp. 48-50.

14. Elokhov A.M., Elokhova T.A. Strategicheskoe programmno-tselevoe upravlenie [Strategic program and goals management]. West Ural Institute of Economics and Law, Perm, 2015, 377 p.

15. Burchakova A.A. Povyshenie ekonomicheskoi effektivnosti energopotrebleniia s ispol'zovaniem mekhanizma energoservisa, kak faktor perekhoda na ustoichivoe razvitie [Energy service for economic efficiency enhancement used for sustainable development]. Ekonomika i predprinimatel'stvo, 2015, no. 12-4, pp. 160-167.

16. Prudskiy V.G., Demin G.A., Oshchepkov A.M., Gershanok A.A. Modern Russian and foreign approaches to strategic planning of the regional socioeconomic development. Journal of Advanced Research in Law and Economics, vol. VIII, Spring, 2(24), pp. 570-580. DOI: 10.14505/jarle.v8.2(24).27.

17. Voevodkin N.Iu., Domozhirova K.V. Osnovy kadrovoi raboty v organizatsii [The personnel of the organization]. Prognozirovanie innovatsionnogo razvitiia natsional'noi ekonomiki v ramkakh ratsional'nogo prirodopol'zovaniia. Proceedings of V Int. Sci.-Pract. Conf., 2016, pp. 434-438.

18. Adeikina T.N., Antipova N.V. Energoservisnyi kontrakt, kak sposob realizatsii politiki energosberezheniia [Energy service contract as a way to implement energy-saving policy]. Molodezh'i nauka. Proceedings of Anniversary All-Russ. Sci.Tech. Stud. Conf., Krasnoyarsk, Siberian Federal University, 2014, available at: http://conf.sfu-kras.ru/sites/mn2014/directions.html (accessed 20 August 2018).

19. Burchakova A.A. Razvitie mekhanizma energoservisa kak napravleniia povysheniia energoeffektivnosti [The development of the energy service mechanism as a direction for improving energy efficiency]. Abstract of Ph.D. thesis, Lomonosov Moscow State University, Moscow, 2016, pp. 134. 
20. Sudenko S. Ekspert o Kompleksnom plane povysheniia energoeffektivnosti ekonomiki Rossii [Expert opinion on the comprehensive energy efficiency plan for the Russian economy]. Portal po energosberezheniiu Energosovet, available at http://energosovet.ru/news.php?zag=1502446427 (accessed 20 August 2018).

21. Gershanok A.A. Rossiiskaia ekonomika na neftianom puti: problemy i perspektivy innovatsionnogo razvitiia predpriiatii [The Russian economy on the oil route: Problems and prospects of innovative development of enterprises]. Industrial'naia tsivilizatsiia: proshloe ili budushchee Rossii. Proceedings of III Perm Congress of Economists, Feb. 17, 2017. Perm, Perm State National Research University, 2017, vol. 1, pp. 21-25.

Оригинальность $79 \%$

Получено 19.10.2018 Принято 11.11.2018 Опубликовано 04.10.2019

\author{
M.V. Marakulin
}

\title{
INTEGRATED STRUCTURE OF INNOVATION ENERGY
} MANAGEMENT SYSTEM IN RUSSIA

The article briefly outlines the prospects for the development of the market of energy services in the Russian Federation and identifies the main reasons for its changes. With the integration of the economy of modern Russia into the global economic system, the role of that part of management activity, aimed at optimization and economical spending of all types of resources consumed by the economy, including energy resources, will grow. The formation of a system of modern energy management in Russia will certainly be characterized by increasingly complex process procedures that will be aimed at solving increasingly complex problems of energy saving. In this regard, the article considers the currently emerging integrated structure of energy management, as well as some process aspects that confirm the specified course of building a hierarchical structure of modern management in the field of energy saving in the Russian Federation.

The process of synthesis of the hierarchy of the energy management system considered in the article is complex. The task implies not only the development of existing innovative practices of the world level, but also the creation of a modern national system of training aimed at the development of technologies of general resource saving. There are shortcomings in certain legislative documents of the federal level defining the policy of development in the field of energy saving. Consideration of the shortcomings of certain provisions and sub-programs of the state program of the Russian Federation «Energy efficiency and energy development», as well as the lack of development of energy saving management system indicates the absence of modern energy management in Russia. The article shows the main directions to overcome the current situation. A number of key factors generating the demand of economic activity participants for energy services, which role will continue to increase, are identified.

Keywords: energy saving, energy efficiency, energy service, energy service contract, legislation in the field of regulation of energy-saving activities.

Mikhail V. Marakulin - Candidate of Economic Sciences, Associate Professor, Department of Management, Perm State National Research University, e-mail: marakperm@mail.ru.

Received 19.10.2018 Accepted 11.11.2018 Published 04.10.2019 